Original Research Article

\title{
Safety and efficacy of palonosetron compared in prevention of postoperative nausea and vomiting in patients undergoing elective major surgery under general anaesthesia
}

\author{
Neha Godre, Mirza Shiraz Baig*
}

Department of Pharmacology, Government Medical College and Hospital, Aurangabad,

Maharashtra, India

Received: 02 October 2019

Revised: 14 November 2019

Accepted: 15 November 2019

\section{*Correspondence to:}

Dr. Mirza Shiraz Baig,

Email: shirazdoctor@yahoo.com

Copyright: () the author(s), publisher and licensee Medip Academy. This is an openaccess article distributed under the terms of the Creative Commons Attribution NonCommercial License, which permits unrestricted noncommercial use, distribution, and reproduction in any medium, provided the original work is properly cited.

\begin{abstract}
Background: Post-operative nausea and vomiting continues to be a common side effect of surgery and anaesthesia, affecting the economics of medical care, as well as the degree of patients' satisfaction, comfort and quality of life. The objective of the present study were to compare the efficacy and safety of palonosetron versus placebo for prophylaxis of early onset (within 24 hours post-surgery) and late onset (24-72 hours post-surgery) post-operative nausea or vomiting in patients undergoing elective major surgery under general anaesthesia.

Methods: A prospective, randomized, parallel group, two arm, double blind placebo controlled trial was conducted on $n=100$ indoor patients undergoing elective major surgeries were enrolled into the present study.

Results: The patients showing complete response were 32 (64\%) in palonosetron group and $19(38 \%)$ in the placebo group $(\mathrm{p}<0.05)$ in the $0-24$ hour time interval. The patients receiving palonosetron showed higher complete response rates in the $0-24$ hour and 0-72 hour time intervals. 42 patients $(84 \%)$ on palonosetron and $30(60 \%)$ on placebo showed complete control of vomiting in 0-24 hour period. Adverse events related to the drug were reported in 5 patients $(10 \%)$ in palonosetron group as compared to 3 patients $(6 \%)$ in placebo group.

Conclusions: A single prophylactic $0.075 \mathrm{mg}$ IV dose of palonosetron effectively reduced the occurrence and severity of nausea and vomiting and delayed the time to emesis and treatment failure in the early as well as the overall postoperative period of 72 hours.
\end{abstract}

Keywords: Palonosetron, Efficacy and safety, Post-operative nausea and vomiting

\section{INTRODUCTION}

Post-operative nausea and vomiting (PONV) remains one of the most common and distressing complications after surgery. PONV untreated occurs in $20-30 \%$ in general surgical population and up to $70-80 \%$ of high risk surgical patients. ${ }^{1,2}$ It also affects the degree of patients comfort, satisfaction, and quality of life. ${ }^{3,4}$ PONV although is self-limiting and non-fatal, it can lead to significant morbidity, dehydration, electrolyte imbalance, suture tension and dehiscence, venous hypertension and bleeding, oesophageal rupture, and life threatening airway compromise, etc. At least seven neurotransmitter types are believed to be implicated in PONV, namely serotonin, dopamine, muscarine, neurokinin-1, histamine and opioids. ${ }^{5}$ antagonists against these neurotransmitters can therefore have an inhibitory effect to prevent or inhibit emesis. ${ }^{6}$ 5HT3 receptor antagonists are safe and do not have the side effects of the commonly used antiemetics, do not affect laboratory tests or cause drug interactions and hence, are increasingly being used for PONV. ${ }^{7,8}$

Palonosetron has been shown to be superior to first generation antagonists in phase III clinical trials for the prevention of acute emesis after moderately emetogenic chemotherapy. $^{9-11}$ Many multiple studies in different 
phases have studied the dose range, efficacy and safety of palonosetron. ${ }^{12-14}$

The present study was planned to assess the safety and efficacy of intravenous $0.075 \mathrm{mg}$ of palonosetron compared with intravenous placebo for the prevention of postoperative nausea and vomiting for the duration of up to 72 hours post-surgery. Global satisfaction of the patients with the antiemetic therapy was also taken into consideration.

\section{Objectives}

The objectives of the present study were to compare the efficacy of palonosetron versus placebo for prophylaxis of early onset (within 24 hours post-surgery) and late onset (24-72 hours post-surgery) post-operative nausea or vomiting in patients undergoing elective major surgery under general anaesthesia, to evaluate the safety and tolerability of palonosetron, in terms of prevention of early onset (within 24 hours post-surgery) and late onset (24-72 hours post-surgery), post-operative nausea or vomiting in patients undergoing elective major surgeries under general anaesthesia.

\section{METHODS}

\section{Study design}

A prospective, randomized, parallel group, two arm, double blind placebo controlled trial.

\section{Procedure}

Hundred patients posted for elective major surgery in surgical, gynaecological, ENT, orthopaedic departments at Government Medical College, Aurangabad (Maharashtra) were enrolled in the study. These patients were randomly allocated into two groups of fifty each. The study was conducted for a period of 1 year (January 2009 to January 2010) after approval of institutional ethics committee.

Each enrolled patient was subjected to a standard protocol for anaesthetic evaluation as well as anaesthesia. Premedication with midazolam or fentanyl was permitted. Induction was performed with thiopentone sodium, intubation using succinylcholine. Anaesthetic maintenance consisted of inhaled drugs (like halothane) plus nitrous oxide. Neuromuscular blocking drugs were used for muscle relaxation with reversal by neostigmine and glycopyrrolate. Postoperative analgesia in the form of tramadol was approved. Medication with antiemetic properties (e.g., propofol) was prohibited. Patients received as per randomization, palonosetron injection (5 $\mathrm{ml}$ vial containing $0.25 \mathrm{mg}$ palonosetron base as hydrochloride) $1.5 \mathrm{ml}$ of the drug $(0.075 \mathrm{mg})$ or $1.5 \mathrm{ml}$ of placebo (normal saline) was injected as a single dose over 30 seconds, 15 minutes prior to anaesthesia, intravenously to every patient.
Since the trial was to study the efficacy of drug in prophylaxis and not treatment of established postoperative nausea or vomiting; and rescue medication for relief of PONV, if occurred, was permitted; withholding a drug was not considered detrimental to patients randomized to placebo, as approved by the concerned anaesthetists.

Follow up was done at 2 hours, 4 hours, 6 hours, 12 hours, 24 hours, 36 hours, 48 hours, 60 hours and 72 hours after injection (i.e., till 3 days after surgery) for complete examination and evaluation of symptom score. Simultaneously any adverse effect due to drug was also enquired.

Evaluation of symptom score for nausea was done by grading of symptoms as absent or present. If present, intermittent or continuous through the day. Severity of nausea was recorded on visual analogue scale (VAS) from 0 to 10 ( 0 - no nausea and 10- severe nausea).

\section{Inclusion criteria}

Patients of either sex in the age group between 18-70 years, patients admitted and posted for elective surgery under general anaesthesia in different surgical departments, patients must have at least two risk factors for PONV, as part of Apfel's score: female gender, a history of PONV and/or motion sickness, or non-smoking status, patients must not be suffering from nausea or any vomiting within 24 hours before beginning study treatment, patients with body performance status between 0 and 2 , and patients ready to give informed consent and abide by the trial procedures.

\section{Exclusion criteria}

Patients admitted in intensive care unit of the hospital for any medication before or after the surgery, patients posted for an emergency surgery, associated multi-organ involvement or septicaemia, patients having concomitant chronic infections, pregnant and lactating females, patients with psychological problem that, in the opinion of the investigator, is severe enough to preclude study participation, patients with known sensitivity to palonosetron and other 5HT3 receptor antagonists and patients who have received any antiemetic medications within last 7 days prior to enrolment.

\section{Efficacy measures}

\section{Primary outcome}

Proportion of patients with complete response during early post-operative period (0-24 hours); late postoperative period (24-72 hours) and during the total postoperative period (0-72 hours) after surgery. Complete response is defined as no occurrence of vomiting during the post-operative period and no use of rescue medication. 


\section{Secondary outcome}

Incidence of nausea and vomiting during early postoperative period ( 0 -24 hours); late post-operative period (24-72 hours) and during the total post-operative period (0-72 hours) after surgery, proportion of patients with complete control of vomiting during early post-operative period (0-24 hours); late post-operative period (24-72 hours) and during the total post-operative period (0-72 hours) after surgery, proportion of patients with failure of treatment control during early post-operative period (0-24 hours); late post-operative period (24-72 hours) and during the total post-operative period (0-72 hours) after surgery, failure is defined as the occurrence of first emetic episode or administration of first dose of rescue medication, whichever occurred earlier, number of emetic episodes during the early and late post-operative periods, time to treatment failure based on the time to first episode, use of rescue medication during early postoperative period (0-24 hours); late post-operative period (24-72 hours) and during the total post-operative period (0-72 hours) after surgery, severity of nausea or vomiting in the early and late post-operative periods and patients' global satisfaction with antiemetic therapy during the early and late post-operative periods.

\section{Safety measures}

Reporting of adverse events and laboratory investigations (before and 3 days after the study), and electrocardiography monitoring done before and within 4 hours of administering the study medication and to avoid observer bias in the study, the operating surgeons performed global assessment of efficacy and tolerability of the medications on a 3-point scale as excellent, good or poor. Similarly, the patients too marked their individual global assessment for medication efficacy and tolerability on the above scale.

\section{Statistical analysis}

Statistical analysis was carried out using students paired ' $t$ ' test for comparing quantitative data within the study groups before and after study. For comparing quantitative data between the study groups after therapy, students unpaired ' $t$ ' test was applied. Also Yates correction or Fisher's exact test with 2-tailed 'p' value where applicable. ANOVA test, with Bonferroni's test for all/selected pairs as the post test was used. Time to treatment failure was assessed by survival analysis using Kaplan-Meier method to create and Log-rank (MantelCox) test to compare the survival curves from raw data.

\section{RESULTS}

A total of $(n=100)$ hundred patients completed the study.

Both groups were similar in all baseline parameters at the start of study as well as in distribution in various surgical faculties.

Table 1: Baseline characteristics.

\begin{tabular}{|lllll|}
\hline S. No. & Parameter & Palonosetron $(\mathbf{n = 5 0})$ & Placebo $(\mathbf{n}=\mathbf{5 0})$ & P value \\
\hline $\mathbf{1}$ & Age $($ years-mean \pm SD) & $38.5 \pm 1.53$ & $36.44 \pm 12.82$ & $>0.05$ \\
\hline $\mathbf{2}$ & Age $($ range) & $18-60$ & $18-63$ & \\
\hline $\mathbf{3}$ & Males & 27 & 26 & $>0.05$ \\
\hline $\mathbf{4}$ & Females & 23 & 24 & $>0.05$ \\
\hline $\mathbf{5}$ & History of PONV and/or motion sickness & 32 & 33 & $>0.05$ \\
\hline $\mathbf{6}$ & Non-smoking status & 50 & 50 & $>0.05$ \\
\hline
\end{tabular}

Table 2: Types of surgeries.

\begin{tabular}{|lll|}
\hline Patients undergoing surgeries in & Palonosetron $(\mathbf{n}=\mathbf{5 0})$ & Placebo $(\mathbf{n}=\mathbf{5 0})$ \\
\hline ENT & 12 & 14 \\
\hline General surgery & 16 & 17 \\
\hline Gynaecology & 10 & 8 \\
\hline Orthopaedics & 12 & 11 \\
\hline
\end{tabular}

The patients receiving palonosetron showed significantly higher complete response rates in the 0-24 hour and 0-72 hour time intervals, i.e., during the early and total postoperative periods respectively. Difference in the two groups at 24-72 hour interval (late postoperative period) was not found to be significant.

Patients in placebo group experienced nausea in the first 24 hours of the postoperative period. This difference was statistically significant $(\mathrm{p}<0.05)$. In the $24-72$ hour period patients in placebo group suffered from nausea. The proportion was higher in placebo group but this difference was not significant $(\mathrm{p}>0.05)$. The incidence of nausea in the overall 72 hours of the study was significantly higher $(\mathrm{p}<0.05)$ in the placebo group than in palonosetron group.

The findings regarding the incidence of vomiting show similar results as those of nausea incidence. Significant difference was observed in the 0-24 hour and 0-72 hour intervals and it was not significant in the 24-72 hour 
intervals. In all patients in early postoperative period of 24 hours $(p<0.05)$ and patients in 24-72 hours $(p>0.05)$ and total patients in the whole of postoperative period of
72 hours $(\mathrm{p}<0.05)$ in palonosetron and placebo groups respectively suffered vomiting.

Table 3: Patients with complete response.

\begin{tabular}{|c|c|c|c|c|c|}
\hline \multirow{3}{*}{ Time interval (hour) } & \multicolumn{4}{|c|}{ Complete response } & \multirow{3}{*}{$P$ value } \\
\hline & \multicolumn{2}{|c|}{ Palonosetron $(n=50)$} & \multicolumn{2}{|c|}{ Placebo $(n=50)$} & \\
\hline & $\mathbf{N}$ & $\%$ & $\mathbf{N}$ & $\%$ & \\
\hline $0-24$ & 32 & 64 & 19 & 38 & $0.0159 *$ \\
\hline 24-72 & 41 & 82 & 36 & 72 & 0.3421 \\
\hline $0-72$ & 24 & 48 & 9 & 18 & $0.0026^{*}$ \\
\hline
\end{tabular}

Table 4: Incidence of nausea and vomiting.

\begin{tabular}{|llllll|}
\hline \multirow{2}{*}{ Time interval (hour) } & \multicolumn{2}{c|}{ Palonosetron $(\mathbf{n = 5 0})$} & \multicolumn{2}{c|}{ Placebo $(\mathbf{n = 5 0})$} & P value \\
\cline { 2 - 6 } & $\mathbf{N}$ & $\mathbf{\%}$ & $\mathbf{N}$ & $\mathbf{\%}$ & $0.0439^{*}$ \\
\hline $0-24$ & 22 & 44 & 33 & 66 & 0.3421 \\
\hline $24-72$ & 9 & 18 & 42 & 84 & $0.0135^{*}$ \\
\hline $0-72$ & 30 & 60 & & & $0.0135^{*}$ \\
\hline Incidence of vomiting & & & 20 & 40 & 0.1595 \\
\hline $0-24$ & 8 & 16 & 7 & 14 & $0.0057^{*}$ \\
\hline $24-72$ & 2 & 4 & 24 & 48 & \\
\hline $0-72$ & 10 & 20 & & & \\
\hline
\end{tabular}

Table 5: Patients with control of vomiting.

\begin{tabular}{|llllll|}
\hline \multirow{2}{*}{ Time interval (hour) } & \multicolumn{2}{l}{ Palonosetron $(\mathbf{n = 5 0})$} & \multicolumn{2}{l|}{ Placebo $(\mathbf{n = 5 0 )}$} & P value \\
\hline $\mathbf{0 - 2 4}$ & $\mathbf{N}$ & $\mathbf{\%}$ & $\mathbf{N}$ & $\mathbf{\%}$ & $0.0135^{*}$ \\
\hline $\mathbf{2 4 - 7 2}$ & 42 & 84 & 30 & 60 & 0.1595 \\
\hline $\mathbf{0 - 7 2}$ & 48 & 96 & 43 & 86 & $0.0057 *$ \\
\hline
\end{tabular}

Table 6: Patients with failure of treatment control.

\begin{tabular}{|c|c|c|c|c|c|}
\hline \multirow{3}{*}{ Time interval (hour) } & \multicolumn{4}{|c|}{ Failure of treatment control } & \multirow{3}{*}{ P value } \\
\hline & \multicolumn{2}{|c|}{ Palonosetron $(\mathrm{n}=\mathbf{5 0})$} & \multicolumn{2}{|c|}{ Placebo $(n=50)$} & \\
\hline & $\mathbf{N}$ & $\%$ & $\mathbf{N}$ & $\%$ & \\
\hline $0-24$ & 18 & 36 & 31 & 62 & $0.0159 *$ \\
\hline 24-72 & 9 & 18 & 14 & 28 & 0.3421 \\
\hline $0-72$ & 26 & 52 & 41 & 82 & $0.0026 *$ \\
\hline
\end{tabular}

Table 7: Number of emetic episodes.

\begin{tabular}{|c|c|c|c|}
\hline \multirow{2}{*}{ Time interval (hours) } & \multicolumn{2}{|l|}{ Number of emetic episodes } & \multirow{2}{*}{ P value } \\
\hline & Palonosetron $(\mathrm{n}=50)($ mean \pm SD $)$ & Placebo $(n=50)($ mean \pm SD $)$ & \\
\hline 0-24 & $0.18 \pm 0.44$ & $0.42 \pm 0.57$ & $0.0208^{*}$ \\
\hline 24-72 & $0.04 \pm 0.20$ & $0.16 \pm 0.42$ & 0.0717 \\
\hline
\end{tabular}

Table 8: Use of rescue medication.

\begin{tabular}{|c|c|c|c|c|c|}
\hline \multirow{3}{*}{ Time interval (hour) } & \multicolumn{4}{|c|}{ Total use of rescue medication } & \multirow{3}{*}{ P value } \\
\hline & \multicolumn{2}{|c|}{ Palonosetron $(\mathbf{n}=\mathbf{5 0})$} & \multicolumn{2}{|c|}{ Placebo $(n=50)$} & \\
\hline & $\mathbf{N}$ & $\%$ & $\mathbf{N}$ & $\%$ & \\
\hline 0-24 & 18 & 36 & 31 & 62 & $0.0159 *$ \\
\hline 24-72 & 9 & 18 & 14 & 28 & 0.3421 \\
\hline $0-72$ & 26 & 52 & 41 & 82 & $0.0026^{*}$ \\
\hline
\end{tabular}


Patients on palonosetron and placebo showed complete control of vomiting in $0-24$ hour period $(\mathrm{p}<0.05)$. In $24-$ 72 hour interval (late postoperative period), vomiting control was seen in patients $(p>0.05)$ in palonosetron and placebo groups respectively. Patients in entire postoperative period of 72 hours in palonosetron and placebo groups respectively showed complete control of vomiting $(p<0.05)$. Statistically significant difference favouring palonosetron was seen in 0-24 and 0-72 hour time intervals. But the difference was not found to be significant in 24-72 hour interval.

Failure of treatment control was the occurrence of first emetic episode or administration of rescue medication dose, whichever was earlier. In all, in 0-24 hour time interval $(p<0.05)$; in $24-72$ hour interval $(p>0.05)$ and patients in overall $0-72$ hour interval of the study in the palonosetron and placebo groups respectively showed failure of treatment control. Patients in the palonosetron group showed significantly better treatment control in early and total postoperative periods than patients in placebo group, but the difference was not significant in 24-72 hours.

The average number of emetic episodes in the palonosetron group was significantly lesser $(\mathrm{p}<0.05)$ than that in placebo group. But the difference was not statistically significant $(\mathrm{p}>0.05)$ between 24 and 72 hours of the study, with the numbers of emetic episodes decreasing to $0.04 \pm 0.20$ in the former and $0.16 \pm 0.42$ in the latter group.

Rescue medication was required in patients of palonosetron group and in patients of placebo group $(p<0.05)$ in the first 24 hours of study. A total of 26 and 41 patients $(\mathrm{p}<0.05)$ in palonosetron and placebo groups respectively needed rescue medication in the entire 72 hour period. The average dose of rescue medication in the palonosetron group at the end of 72 hours, verses placebo group was statistically highly significant $(\mathrm{p}<0.001)$ indicating a significantly lesser requirement in palonosetron group.

Using VAS of 0-10, severity of nausea in 0-24 hour interval in the palonosetron group, compared to placebo group notifies that it was more severe in placebo group and the difference was highly significant $(\mathrm{p}<0.001)$.

The scores decreased in 24-72 hours in palonosetron and in placebo groups. This difference was not found to be statistically significant $(\mathrm{p}>0.05)$.

Table 9: Severity of nausea and vomiting.

\begin{tabular}{|llll|}
\hline Severity of nausea & & & \\
\hline Time interval (hour) & Palonosetron $(\mathbf{n}=\mathbf{5 0})(\mathbf{m e a n} \pm \mathbf{S D})$ & Placebo $(\mathbf{n}=\mathbf{5 0})(\mathbf{m e a n} \pm \mathbf{S D})$ & P value \\
\hline $0-24$ & $1.69 \pm 2.16$ & $3.74 \pm 3.10$ & $0.0002^{* *}$ \\
\hline $24-72$ & $0.63 \pm 1.39$ & $1.39 \pm 2.51$ & 0.0622 \\
\hline Severity of vomiting & & & $0.0014^{*}$ \\
\hline $0-24$ & $0.68 \pm 1.64$ & $2.20 \pm 2.83$ & $0.0361^{*}$ \\
\hline $24-72$ & $0.14 \pm 0.72$ & $0.76 \pm 1.92$ & \\
\hline
\end{tabular}

Table 10: Comparative global assessment of efficacy and tolerability judged by the surgeon and patient after study in both the groups.

\begin{tabular}{|lllll|}
\hline \multirow{2}{*}{ Global assessment } & & Palonosetron & Placebo & 'P' value \\
\hline \multirow{3}{*}{ Surgeon-efficacy } & & $\mathbf{N}(\%)$ & $\mathbf{N}(\%)$ & $0.0022^{*}$ \\
& Excellent & $23(46)$ & $8(16)$ & 0.6242 \\
\cline { 2 - 5 } & Good & $9(18)$ & $12(24)$ & $0.0272^{*}$ \\
\cline { 2 - 5 } Patient-efficacy & Poor & $18(36)$ & $30(60)$ & 0.0076 \\
& Excellent & $21(42)$ & $8(16)$ & 1.0000 \\
\cline { 2 - 5 } & Good & $9(18)$ & $10(20)$ & 0.0272 \\
\cline { 2 - 5 } Surgeon-tolerability & Poor & $20(40)$ & $32(64)$ & 0.7150 \\
\hline \multirow{3}{*}{ Patient-tolerability } & Excellent & $45(90)$ & $47(94)$ & 0.7150 \\
\cline { 2 - 5 } & Good & $5(10)$ & $45(90)$ & 0.5536 \\
\cline { 2 - 5 } & Excellent & $42(84)$ & $2(4)$ & 0.2687 \\
\cline { 2 - 5 } & Good & $6(12)$ & $3(6)$ & 1.0000 \\
\hline
\end{tabular}

To remove observer bias from the study, the treating surgeons (blinded) and the patients were asked to assess the efficacy and tolerability of the medications in both groups at the end of 72 hours. The surgeons found that efficacy of palonosetron was excellent in 23 patients (as opposed to 8 of placebo- a significantly less number$\mathrm{p}<0.05$ ) and good in 9 patients (as opposed to 12 of placebo, difference not being significant with $\mathrm{p}>0.05$ ). 
Palonosetron was marked as poor in 18 patients, the number being significantly less $(\mathrm{p}<0.05)$ compared to 30 patients in the placebo group. The efficacy assessment by the patients was found to be similar to that of the surgeons. 21 patients rated palonosetron as excellent, 9 patients found it to be good, while 20 patients marked its efficacy as poor. Placebo was found to be excellent by 8 patients, good by 10 , while it was found to be poor by 32 patients (significant difference, favouring palonosetron as $\mathrm{p}<0.05)$.

Tolerability of study medications was found to be comparable in both the groups $(\mathrm{p}>0.05)$ as assessed by both, the surgeons and patients. Thus, palonosetron was well tolerated as the adverse events were of mild to moderate intensity and were similar in both groups $(\mathrm{p}>0.05)$.

\section{DISCUSSION}

PONV remains one of the most common and distressing complications after surgery. PONV untreated occurs in $20-30 \%$ in general surgical population and up to $70-80 \%$ of high risk surgical patients. ${ }^{2}$

Although the efficacy of antiemetic therapy for prevention and treatment of PONV has been frequently studied, it is not well understood. ${ }^{3}$ Moreover, current interventions lack universal efficacy, especially as monotherapy. ${ }^{5}$ Due to side effects and increased restrictions on use of other antiemetic agents, $5 \mathrm{HT}_{3}$ receptor antagonists are increasingly being used for PONV. ${ }^{8,10}$

The results of present study showed a statistically significant difference in the complete response rates in the first 24 hours and overall 72 hours post-surgery, response being more with palonosetron. Even in the 2472 hour interval, complete response rates were higher with palonosetron; the difference however was not significant. These findings are in accordance with the studies carried which reported significant difference in complete response rates in all three time intervals. ${ }^{13,14}$

A significant lower incidence of nausea in the palonosetron group as compared with placebo in 0-24 hour and 0-72 hour intervals was noted. The difference in intensity (severity), again lower with palonosetron was highly significant in first 24 hours. But, neither incidence nor severity was significant in 24-72 hour interval. These results are similar to those studies who reported significantly lesser findings with palonosetron 0.075 mg. ${ }^{13,14}$

The incidence of vomiting was lower and proportion of patients with complete control of vomiting was higher with palonosetron throughout the current study, the difference being statistically significant in the first 24 hours and overall 72 hours post-surgery but not between 24 and 72 hours. A lower incidence of vomiting with palonosetron $0.075 \mathrm{mg}$ but no statistically significant difference in any time interval was reported in different studies. $^{13,14}$

There was comparable occurrence of drug related adverse events (headache, constipation, diarrhoea) and no serious event. There was no significant change in QTc interval on the electrocardiography before and during the study period. Similar finding was reported by different studies. $^{13,14}$

Results suggest that palonosetron appears to be associated with an overall downward shift in the PONV incidence. The proportion of patients with failure of treatment control and use of rescue medication was higher in placebo group than in palonosetron group, which was statistically significant in early (0-24 hour) and total (0-72 hour) postoperative periods. The findings correlate with studies showing an overall significant difference with more use of rescue medication in placebo group. The finding points towards the longer lasting mechanism of action of palonosetron. ${ }^{13,14}$

The global satisfaction of patients with antiemetic therapy was significantly more at the end of 24 hours in those receiving palonosetron than those receiving placebo. Even at the end of 72 hours, the global satisfaction rating was higher in palonosetron group but the difference was not significant. Global assessment of efficacy judged by the surgeon and the patient in the current study was good to excellent in most of the palonosetron group patients and poor in most of the patients on placebo. The present study found palonosetron to be significantly better than placebo for most of the efficacy parameters for the evaluation period. Improved control by placebo, particularly in the late postoperative period (24-72 hours), perhaps, was a reflection of the use of rescue medication in the early postoperative period (0-24 hours) post-surgery.

\section{CONCLUSION}

These findings indicate successful fulfilment of important needs such as protection against nausea and vomiting in patients at risk for PONV and justify the significantly higher global satisfaction of patients with palonosetron therapy, at least in the early postoperative period. Palonosetron thus can be preferred as a prophylactic antiemetic during major elective surgeries.

Funding: No funding sources

Conflict of interest: None declared

Ethical approval: The study was approved by the Institutional Ethics Committee

\section{REFERENCES}

1. Pasricha PJ. Treatment of disorders of bowel motility and water flux; antiemetics; agents used in biliary and pancreatic disease. In: Brunton LL, Lazo JS, 
Parker KL, eds. Goodman and Gilman's the pharmacological basis of therapeutics. 11th ed. New York: McGraw-Hill; 2006: 983-1008.

2. Gan TJ, Meyer TA, Apfel CC, Chung F, Davis PJ, Habib AS, et al. Society for ambulatory anesthesia guidelines for the management of postoperative nausea and vomiting. Anesth Analg. 2007;105(6):1615-28.

3. Kovac AL. Prevention and treatment of postoperative nausea and vomiting. In: Donnerer J, ed. Antiemetic Therapy. Basel: Karger; 2003: 121-160.

4. Stadler M, Bardiau F, Seidel L, Albert A, Boogaerts JG. Difference in Risk Factors for Postoperative Nausea and Vomiting. Anesthesiol. 2003;98(1):4652.

5. Gan TJ. Risk factors for postoperative nausea and vomiting. Anesth Analg. 2006;102(6):1884-98.

6. Watcha MF, White PF. Postoperative nausea and vomiting. Its etiology, treatment, and prevention. Anesthesiol. 1992;77(1):162-84.

7. Donnerer J, Beubler E. 5-HT3 Receptor Antagonists in Antiemetic Therapy. In: Donnerer J, ed. Antiemetic therapy. Basel: Karger; 2003: 22-32.

8. McQuaid KR. Drugs used in the treatment of gastrointestinal diseases. In: Katzung BG, Masters SB, Trevor AJ, eds. Basic and clinical pharmacology. 11th ed. New Delhi: Tata McGraw-Hill; 2009: 10671102.

9. Palonosetron full prescribing information (label). Available at: drugs@fda.gov.http://www.accessdata. fda.gov/drugsatfda_docs/label/2008/021372s008s010 lbl.pdf. Accessed on 10 October 2019.

10. Muchatuta NA, Paech MJ. Management of postoperative nausea and vomiting: focus on
Palonosetron. Ther Clin Risk Manag. 2009;5(1):2134.

11. Rojas C, Stathis M, Thomas AG, Massuda EB, Alt J, Zhang $J$, et al. Palonosetron exhibits unique molecular interactions with the 5-HT3 receptor. Anesth Analg. 2008;107(2):469-78.

12. Botrel TE, Clark OA, Clark L, Paladini L, Faleiros E, Pegoretti B. Efficacy of palonosetron (PAL) compared to other serotonin inhibitors (5-HT(3)R) in preventing chemotherapy-induced nausea and vomiting (CINV) in patients receiving moderately or highly emetogenic (MoHE) treatment: systematic review and meta-analysis. Support Care Cancer. 2011;19(6):823-32.

13. Candiotti KA, Kovac AL, Melson TI, Clerici G, Gan TJ. A randomized, double-blind study to evaluate the efficacy and safety of three different doses of palonosetron versus placebo for preventing postoperative nausea and vomiting. Anesth Analg. 2008;107(2):445-51.

14. Kovac AL, Eberhart L, Kotarski J, Clerici G, Apfel C. A randomized, double-blind study to evaluate the efficacy and safety of three different doses of palonosetron versus placebo in preventing postoperative nausea and vomiting over a 72-hour period. Anesth Analg. 2008;107(2):439-44.

Cite this article as: Godre N, Baig MS. Safety and efficacy of palonosetron compared in prevention of postoperative nausea and vomiting in patients undergoing elective major surgery under general anaesthesia. Int J Basic Clin Pharmacol 2019;8: 257884. 